\title{
PRIMJENA MAKE OR BUY ANALIZE PRI STRATEŠKOM ODLUČIVANJU U LANCIMA SNABDJEVANJA
}

\section{THE USE OF MAKE OR BUY ANALYSIS FOR STRATEGIC DECISION MAKING IN THE SUPPLY CHAIN}

\author{
Slobodan Ilić, Fakultet tehničkih nauka, Novi Sad
}

\begin{abstract}
Oblast - SAOBRAĆAJ
Kratak sadržaj - U prvom dijelu rada prikazana je teorijska osnova radi boljeg razumjevanja pojma lanca snabdjevanja, uloge skladišta u lancu snabdjevanja, kao $i$ trendova koji utiču na strategiju upravljanja lancima snabdjevanja. $U$ drugom dijelu ovog rada prikazana je primjena analize „napraviti ili kupiti“ (engl. make or buy) za donošenje strateških odluka sa posebnim akcentom na primjenu tehnike ,tačke poravnanja“ (engl. break even point).
\end{abstract}

Ključne reči: upravljanje lancem snabdjevanja, skladište, „, make or buy“, ,, break even point“

\begin{abstract}
The first part of the paper presents the theoretical basis for a better understanding of the supply chain concept, the role of warehouse in the supply chain, as well as the trends that affect the supply chain management strategy. The second part of this paper will outline the use of "make or buy" analysis in order to make strategic decisions, with particular emphasis on the application of the "Break Even point".
\end{abstract}

Keywords: supply chain management, warehouse, "make or buy", "Break Even point"

\section{UVOD}

Kada se govori o konkurentnosti na tržištu, trenutna situacija u svjetu primorava kompanije da preispituju svoje postojeće procese, tehnologije i usluge u cilju fokusiranja na strateške aktivnosti. Outsourcing se danas sve više koristi kao konkurentsko oružje posmatrano sa ekonomskog aspekta. Provajderi usluga često mogu posao obavljati brže, jeftinije i bolje. To je rezultovalo sve većom svješću o važnosti odluke ,napraviti ili kupiti“ (engl. make or buy), sa kojom se suočavaju organizacije kada odlučuju između realizacije logističkih usluga u „kući“ ili „kupovinom“ od provajdera logističkih usluga. $\mathrm{U}$ ovom radu analizira se slučaj kompanije $X$, koja zbog povećanja obima posla razmatra da li iznajmljivati skladište ili praviti sopstveno. Tema ovog rada je prikaz primjene make or buy analize prilikom donošenja pomenute strateške odluke. U radu, prvo je dat prikaz osnovnih pojmova, kao i svih faza kroz koje je potrebno proći kako bi se dobio odgovor na pitanje da li nešto samostalno raditi ili kupiti uslugu.

\section{NAPOMENA:}

Ovaj rad proistekao je iz master rada čiji mentor je bio dr Marinko Maslarić, vanr. prof.
U drugom delu rada predstavljena je studija slučaja, čiji osnovi cilj je bio dobijanje odgovora na pitanje da li iznajmljivati ili praviti sopstevno skladište. Kao pogodna inženjerska tehnika za odgovor na ovo pitanje koristila se analiza „tačke poravnanja“ (engl. Break Even Point).

\section{LOGISTIKA I UPRAVLJANJE LANCIMA SNABDJEVANJA}

Logistika je relativno novo polje u sferi upravljanja, u poređenju sa tradicionalnim oblastima kao što su finansije, marketing, proizvodnja. U prošlosti logističke aktivnosti u kompanijama su se realizovale međusobno neusaglašeno i parcijalno. Međutim, pojava koncepta koordinisanog i integirsanog upravljanja povezanim aktivnostima dovela je do znatnog boljih rezultata od postojeće prakse nezavisnog upravljanja pojedinim logističkim aktivnostima, jer logistika dodaje vrijednost proizvodima i uslugama koja je neophodna za zadovoljenje krajnjih potrošača [1].

Prvo navođenje termina logistika, naravno u vojnom kontekstu, pojavljuje se u radovima s kraja 19. veka. U radovima se navodi kako ,strategija predstavlja umetnost rukovanja trupama u teatru zvanom rat; taktika je njihovo rukovanje na bojnom polju u toku same bitke... Francuzi imaju i treći proces, koji nazivaju logistika, a koji predstavlja umjetnost premještanja i snabdjevanja trupa.“” Kada se govori o definicijama u novije vrijeme, u većini slučajeva dolazi do njenih poređenja ili preplitanja sa terminom upravljanje lancima snabdjevanja. $\mathrm{Na}$ osnovu prezentovanih definicija može se izvesti generalni zaključak [1], da se pod logistikom podrazumjevaju sve aktivnosti vezane za prostornu i vremensku transformaciju tokova roba i njima pripadajućih tokova informacija, finansija i usluga.

Veoma je teško, skoro i nemoguće u današnje vrijeme da jedna organizacija (kompanija) kontroliše kompletan tok materijalnih dobara, počevši od izvora sirovina pa sve do izrade krajnjeg proizvoda i stavljanja na upotrebu korisniku. U današnje vrijeme, u većini slučajeva, koriste se različiti dobavljači sirovina, materijala, proizvoda, poluproizvoda i slično, kao i usluge provajdera usluga u pogledu pružanja logističkih usluga.

Prema određenim autorima lanac snabdjevanja se definiše kao: „niz sekvencijalno povezanih organizacija i aktivnosti zajednički uključenih u kreiranje i stvaranje proizvoda“. Autori takođe ističu da se lanac snabdjevanja može posmatrati i kao lanac vrijednosti (eng. value chain), pošto snabdjevači, proizvođači, transporteri i svi ostali u 
lancu snabdjevanja dodaju određenu vrijednost proizvodu. Takođe ističe se i mogućnost obrnutog posmatranja toka navedenih aktivnosti, što može dovesti do toga da se lanac snabdjevanja posmatra kao lanac potražnje (eng. demand chain).

Nakon izloženih definicija lanca snabdjevanja iz različitih izvora od strane različitih autora, mogući rezime navedenih definicija bi glasio [1] da lanac snabdjevanja predstavlja skup organizacija koje obezbjeđuju da se u jednom integrisanom procesu sirovine prerađuju u finalne proizvode i zatim isporučuju krajnjim korisnicima, odnosno, lanac snabdjevanja čine svi fizički elementi i njihovi međusobni odnosi predstavljeni preko odgovarajućih funkcija i aktivnosti.

\section{FAZE ODLUČIVANJA I ULOGA SKLADIŠTA U LANCU SNABDJEVANJA}

U prethodnom poglavlju lanac snabdjevanja je definisan kao skup fizičkih elemenata (infrastruktura) i njihovih aktivnosti i procesa kroz koje se odvija njihova međusobna interakcija (modeli ponašanja fizičkih elemenata). Oblikovanje fizičke infrastrukture je problem strateške prirode, dok je planiranje i projektovanje egzekutabilnog dijela lanca snabdjevanja (definisanje odgovarajućih način, modela $\mathrm{i}$ pravila realizacije pojedinih aktivnosti i procesa) po svojoj prirodi više taktičko ili operativno. Prema tome, upravljanje lancem snabdjevanja predstavlja:

- strateško oblikovanje infrastrukturnih elemenata

(veličine, broja, lokacija, itd.);

- taktičko projektovanje politika ponašanja elemenata i

- planiranje operativnog funkcionisanja elemenata lanca snabdjevanja.

Upravljanje lancima snabdjevanja treba da odgovori na pitanja: šta, kada i kako? Kao što se može vidjeti, sve odluke vezane za upravljanje lancem snabdjevanja mogu se svrstati u tri kategorije ili faze, zavisno od frekvencije svake odluke i od vremenskog okvira u kojem je faza odlučivanja realizovana: strateške, taktičke i operativne. Strateško planiranje podrazumjeva planiranje na duge staze, gde je vremenski period duži od jedne godine. Taktičko planiranje i odlučivanje uključuje srednji vremenski period, obično kraći od jedne godine. Operativno planiranje predstavlja kratkoročno donošenje odluka, često na svakih sat vremena, a najčešće na nivou dana ili nedelje.

Za razliku od transporta, skladištenje i manipulisanje robom odvija se u čvorovima lanaca snabdjevanja. Sve organizacije drže rezerve (zalihe). Zalihe mogu nastati u bilo kojoj tački lanca snabdjevanja gdje je protok materijala prekinut. Većina organizacija se odlučuje da svoje rezerve drže u skladištima. Često se za skladišta u praksi može čuti da su ona: ,transport sa brzinom kretanja od 0 kilometara" [2].

U literaturi se koriste različiti termini za skladište, najčešći su distributivni centar ili logistički centar. Termin distributivni centar uglavnom se koristi kako bi se naznačila razlika $\mathrm{u}$ odnosu na skladišta primarno namjenjena za dugotrajno čuvanje i skladištenje robe. Zbog velikog broja različitih termina, u ovom radu je korišćen termin ,skladište”.
Skladišta su skupa za vođenje i zahtjevaju pažljivo planiranje. Logistička strategija koja je bazirana na globalnoj strukturi lanca snabdjevanja, neophodno je da u sastavu strukture lanca uključujući ulogu skladišta. Na strategijskom nivou donose se odluke o lokaciji skladišta, planovi kapaciteta pokazuju broj potrebnih skladišta kao i njihov kapacitet, menadžment zaliha pokazuje koji asortiman i količinu materijalnih dobara treba skladištiti. Prilikom donošenja navedenih odluka, logističari su suočeni sa nizom pitanja i nedoumica. Osnovna funkcija skladišta je da skladišti robu. Primarne aktivnosti skladišta se ogledaju u tome da prihvate dostavljenu robu, izvrše sve potrebne provjere prije uskladištenja, da uskladište robu i čuvaju je dok se ne ukaže potreba za njom. Kada se ukaže potreba za otpremom robe, vrši se raspoređivanje robe po krajnjim destinacijama i organizuje dostave do krajnjih korisnika.

Aktivnosti koje se odvijaju u skladištima mogu se podjeliti u dvije važne funkcije: držanje zaliha (skladištenje) i manipulisanje materijalima. Pod manipulisanjem materijalima podrazumjevaju se procesi utovara i istovara robe, unutrašnji transport sa robom i komisioiranje. Skladištenje se pojednostavljeno može posmatrati kao akumuliranje zaliha tokom vremena.

Danas, organizacije pokušavaju da premjeste materijale brzo kroz lanac snabdjevanja, te se uloga skladišta postepeno mijenja. Skladišta se danas posmatraju kao stacionarne tačke kroz koje se materijal kreće što je brže moguće. Vremenom uloga skladišta u lancu snabdjevanja se mjenjala, pa su pored osnovne aktivnosti (skladištenje robe) postala pogodna za razne druge aktivnosti. Skladišta su na primjer najbolja mjesta za sortiranje materijala, pakovanje i konsolidovanje dostava.

Mnoge organizacije posjeduju i vode svoja skladišta. To su uglavnom kompanije koje imaju razvijena tržišta, potražnju i dugoročni strategijski plan poslovanja u određenom regionu. Za male kompanije problem skladišta je veliki, jer one često nisu ni finansijskini organizaciono spremni da vode i upravljaju kompleksnim skladišnim sistemom. Sa druge strane male kompanije takođe imaju potrebu za skladištem kao važnim čvorom u njihovim lancima snabdjevanja [2]. Kao moguće rješenje, javljaju se skladišta kojima upravljaju kompanije koje su usko specijalizovane za skladišno poslovanje. Često se i velike kompanije nalaze u dilemi da li da povjere čuvanje svojih zaliha drugim kompanijama ili da vrše izgradnju svog skladišta, te se osnovna podjela skladišta prema vlasničkoj strukturi može izvršiti na: privatna i javna skladišta.

\section{TRENDOVI KOJI UTIČU NA STRATEGIJU UPRAVLJANJA LANCIMA SNABDJEVANJA}

Preduzimanje različitih aktivnosti u cilju pronalaženje balansa između logističke efikasnosti i odziva (reagibilnosti), doprinijelo je kreiranju "novih" trendova u oblasti upravljanja lancima snabdjevanja. $\mathrm{Na}$ osnovu pregleda literature, navedene aktivnosti je moguće klasterizovati $\mathrm{u}$ sledećih nekoliko trendova [1]:

- integracija lanaca snabdjevanja,

- troškovna efikasnost (lean logistika),

- povećanje reagibilnosti (agilna logistika),

- smanjenje broja snabdjevača i

- outsourcing. 
Sourcing predstavlja process prenošenja posla sa jednog na drugi entitet, dok outsourcing predstavlja proces prenošenja posla na provajdera usluge. Outsoucring [3] predstavlja još jedan način za povećanje efektivnosti. $U$ današnje vrijeme dolazi do velikog broja odluka za kompanije, kako malih (na operativnom nivou), tako i velikih, odnosno strateških koje predstavljaju određene dugoročne ciljeve kompanije, kao i neka dugoročna ulaganja ( $u$ infrastrukturu, transportna sredstva i slično). Pojavom velikih kompanija, kao i pojavom globalizacije dolazi do određenih promjena u lancima snabdjevanja. Odlučivanje da li će se vršiti outsourcing svodi se na odluku da li nešto ,napraviti ili kupiti“ (engl. make or buy). Organizacije se neprestano suočavaju sa odlukom da li da povećaju resurse radi stvaranja sredstava, drugih resursa, proizvoda ili usluge interno ili da ih kupe od spoljnih provajdera.

Ovaj rad pruža uvid u metodologiju odlučivanja putem make or buy metode, koju bi bilo koji menadžer mogao da implementira, bez obzira na veličinu organizacije ili industriju kojoj ona pripada. Make or buy metodologija je jedna od najkritičnijih strateških odluka u okviru logističkog outsourcing-a i treba da bude donijeta na strukturiran i konzistentan način. Pregledom literature na ovu temu u nastavku rada je prikazan proces donošenja odluka make or buy metodom sa aspekta određenih autora, kao i studija slučaja primjene ove metode za donošenje strateške odluke. U nastavku rada, studija slučaja će se bazirati na primjeni jednostavnih matematičkih metoda, bez prevelikog nivoa detaljnosti koje bi trebala da sadrži bilo koja strateška odluka, ali će nam dati odgovor na postavljeno pitanje: praviti ili kupiti?

Za aktivnosti koje se razmatraju za outsourcing, ključno je strateško pitanje da li kompanija može obavljati te uslužne aktivnosti na nivou koji je uporediv sa najboljim organizacijama na svijetu. Ako uslužna aktivnost ispunjava određene kriterijume, sledeći korak je odlučivanje da li je usluga od centralnog značaja u osnovnim strateškim aktivnostima firme.

Štaviše, da bi donijele najbolju odluku u okviru make or buy analize, kompanije moraju da utvrde kako će ta odluka uticati na kvalitet konačnog proizvoda i kompanijsku tehnologiju. Prilikom donošenja make or buy odluke, potrebno je proći kroz nekoliko faza [3]:

- faza planiranja,

- faza procjene,

- faza analiziranja, i

- faza izbora dobavljača.

\section{STUDIJA SLUČAJA ZA KOMPANIJU X}

Iako na prvi pogled ova metoda može izgledati kao veoma jednostavna, kompleksnost ove metode prilikom primjene $\mathrm{u}$ realnosti zavisi od odluke tj. odgovora (napraviti ili kupiti) koji želi da se postigne ovom metodom. Svaka analiza ne mora da znači da će u potpunosti oslikavati realno stanje, ali se teži da se što preciznije prikaže. Cilj ovog poglavlja je prikaz analize make or buy uz pomoć jednostavnih inženjerskih tehnika, koje mogu doprinijeti stvaranju prave sliku o konkretnim troškovima koje treba razmotriti. Takođe, prilikom analize neće se detaljno zadirati u ekonomske aspekte ovog projekta, ali će se prikazati dobra osnova za dalje razmatranje jedne od odluka tj. da li nešto napraviti ili kupiti.
Kompanija $X$ zbog povećanja obima posla, razmatra pravljenje svog ili angažovanje spoljnog skladišta.

Buduće skladište u kompaniji X, koje se razmatra u okviru ovog poglavlja, predstavlja konsolidacioni centar, u kome će dolaziti veće količine materijala, a nakon toga, kada se javi potreba za materijalima, manje količine će se isporučivati na mjesta potrošnje. Skladišni kapaciteti koji se razmatraju u ovoj odluci su oko $1500 \mathrm{~m}^{2}$ zatvorenog skladišnog prostora. Prilikom istraživanja u kompaniji $X$, menadžeri su pronašli odgovarajuće skladiše (sa aspekta cijene i lokacije), koje bi se razmatralo prilikom opcije kupiti-buy.

Cijena mjesečnog zakupa za izabrano skladište iznosi 2,5 $€ / \mathrm{m}^{2}$, što iznosi $45.000 € /$ godišnje. Potrebno je napomenuti da razmatrano skladište ne posjeduje radnu snagu, radnike obezbjeđenja, kao ni transportno-maniuplativna sredstva, pa će se ovi troškovi takođe zanemariti prilikom opcije praviti-make.

Prilikom istraživanja podataka za cenu izgradnje sopstvenog skladišta, preuzimani su podaci o cijeni tipskih skladišta [4], dok je cijena zemljišta analizirana pomoću internet pretrage. Cijena objekta sa zemljištem iznosi $278.893 €$, za skladište od $1.500 \mathrm{~m}^{2} \mathrm{i}$ zemljište od 5.000 $\mathrm{m}^{2}$. Troškovi kupovine zemljišta i izgradnje zatvorenog skladišta predstavljaju investicione troškove koji se pojavljuju samo u početnoj godini, dok se ostali troškovi (amortizacije i režija) javljaju svake godine. Godišnji iznos amortizacije utvrđen je po formuli:

god.iznos amor. $=$ osnovica za amor.x god.stopa amor. $[€ /$ god $]$

god.stopa amortizacije $=$

100/(korisni vijek trajanja objekta) [\%]

Korisni vijek trajanja objekta je 15 godina, pa su troškovi amortizacije $16.268 €$ /godišnje. Troškovi režija su proračunati na osnovu troškova koji se javljaju u drugim skladištima kompanije $X$, posmatrano na osnovu sličnih skladišnih kapaciteta, i oni iznose $1.300 €$ /godišnje.

Kao jedna od tehnika koja se često koristi prilikom make or buy odluke je analiza „tačke poravnanja” (engl. Break Even Point). Analiza ,tačke poravnanja” se najčešće koristi za odgovor na pitanja poput "koji je minimalni nivo prodaje koji osigurava da kompanije ne doživi gubitak" ili "koliko prodaja može opasti, a da kompanija i dalje posluje pozitivno" [5]. Tačka poravnanja može se utvrditi prema opštoj formuli:

pri čemu je:

$$
K q p=\frac{T_{\varphi}}{C_{\varphi}-T_{\pi \varphi}}
$$

- Kqp - procenat korišćenja kapaciteta na tački ekonomičnosti (u zavisnosti šta se želi prikazati kao izlazni rezultat, $K q p$ može biti prikazan u različitim mjernim jedinicama);

- $\mathrm{T} \varphi$ - fiksni troškovi u ukupnom iznosu;

- $\mathrm{Cq}$ - konstantni troškovi;

- $\mathrm{T} \pi \varphi$ - proporcionalni troškovi po jedinici proizvoda.

$\mathrm{Na}$ osnovu gore navedenih podataka, može se postaviti formula na sledeći način:

pri čemu je:

$$
K q p=\frac{T_{\varphi}}{C_{\varphi}-T_{\pi \varphi}}[\text { broj godina }]
$$


- Kqp - godina u kojoj će se troškovi iznajmljivanja skladišta i troškovi izgradnje sopstevnog skladišta izjednačiti;

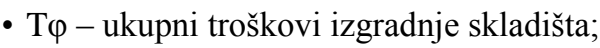

- $\mathrm{Cq}$ - konstantni troškovi iznajmljivanja skladišta;

- $\mathrm{T} \pi \varphi$ - troškovi koji se javljaju svake godine za sopstveno skladište.

Nakon unosa podataka u prikazanu formulu, dobija se sledeći rezultat (slika 5.1):

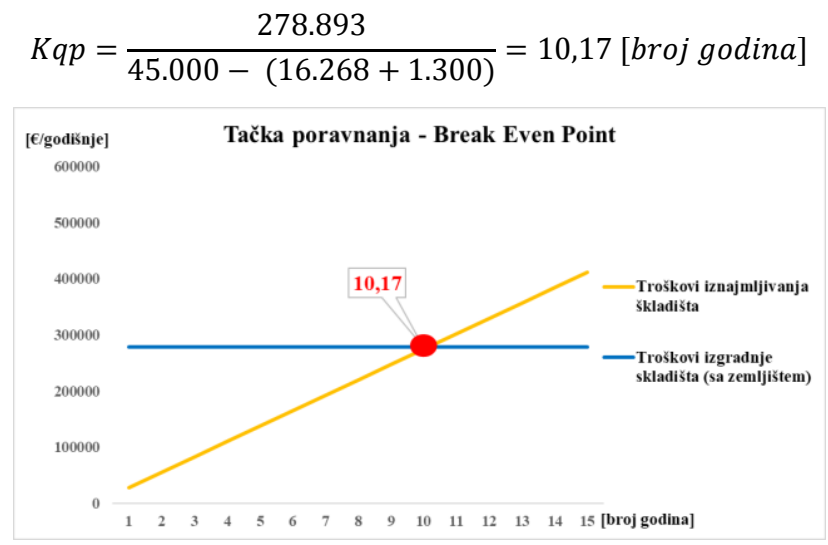

Slika 1: Grafički prikaz ,tačke poravnanja“

Ukoliko se donose odluka o izgradnji skladišta (pod pretpostavkom da troškovi izgradnje skladišta odgovaraju troškovima prikazanim u poglavlju 5) umjesto iznajmljivanja pomenutog skladišta, troškovi iznajmljivanja I troškovi izgradnje skladišta će se izjednačiti u trećem mjesecu $(0,17 * 12$ mjeseci $=2.04 \sim 3)$, jedanaeste godine eksploatacije.

\section{ZAKLJUČNA RAZMATRANJA I PRAVCI DALJIH ISTRAŽIVANJA}

Da bi se dobio odgovor da li kompanija $X$ da pravi sopstveno skladište ili da iznajmljuje, potrebno je prije toga odgovoriti na pitanje: Za koji period se predviđa upotreba skladišta?

Zbog povjerljivosti podataka kompanije, kao i oblasti kojom se bavi pomenuta kompanija, u ovom radu nije bilo moguće odgovoriti na pitanje da li napraviti ili kupiti.
Zahvaljujući primjenjenoj tehnici (Break Even Point) na osnovu dobijenih rezultata prilikom proračuna, može se zaključiti sledeće: ukoliko bi podaci koji su korišćeni odgovarali u potpunosti realnom stanju, za period od 10 godina i 2 mjeseca bolje je iznajmljivati skladišni prostor. Nakon ovog perioda, kao bolja opcija (ekonomski isplativija) bi bila izgradnja sopstevnog skladišta.

Ukoliko bi kompanija $X$ imala potrebu za korišćenjem skladišta na vremenski period duži od 10 godina i 2 mjeseca, potrebno je da se prije izgradnje utvrde osnovni parametre investicionog vrednovanja (NSV - neto sadašnja vrijednost, IR - indeks rentabilnosti itd.), kao i da se definiše optimalna lokacija skladišta u odnosu na potrebe. Takođe, još jedan od faktora koje je potrebno razmotriti pri donošenju konačne odluke je koje su prednosti/nedostaci sopstvenog skladišta.

\section{LITERATURA}

[1] Maslarić M., Osnove upravljanje lancima snabdevanja, FTN Novi Sad

[2] Mirčetić D., Logistički centri - skripta za vežbe, FTN Novi Sad, 2016.

[3] Bajec P., Jakomin I., A make or buy decision process for outsourcing, Faculty of Maritime Studies and Transportation Portorož, Jul. 2010.

[4] http://www.argus-eng.co.rs/proizvodi/tipske-haleargus-cenovnik/ (pristupljeno u novembru 2019.)

[5] Petković, S., iBerberović, Š., Ekonomika i upravljanje malim i srednjim preduzećima. Principi i politike., Ekonomski fakultet Banja Luka, 2013.

\section{Kratka biografija:}

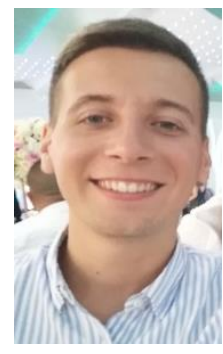

Slobodan Ilić rođen je u Bijeljini 21.05.1995. godine. Tehničku školu „Mihajlo Pupin“, smjer Tehničar drumskog saobraćaja završava 2014. godine, a iste godine upisuje Saobraćaj i transport na FTN-u u Novom Sadu, na kome u septembru 2018. godine stiče zvanje diplomiranog inženjera saobraćaja.

kontakt: slobodan_bn@hotmail.com 